\title{
A case of dyspnea: respiratory failure due to pulmonary arteriovenous malformation
}

\author{
Lucio Brugioni, ${ }^{1}$ Chiara Catena, ${ }^{2}$ Eugenio Ferraro, ${ }^{2}$ Serena Scarabottini, ${ }^{2}$ Francesca Mori, ${ }^{2}$ Enrico Clini ${ }^{3}$ \\ ${ }^{1}$ Department of Internal Medicine and Critical Area, Policlinico of Modena; ${ }^{2}$ Department of Internal Medicine and Critcal \\ Area, University of Modena and Reggio Emilia; ${ }^{3}$ Department of Pneumology, Policlinico of Modena, Italy
}

\begin{abstract}
Pulmonary arteriovenous malformations (PAVMs) are abnormal communications between pulmonary arteries and veins. The clinical features suggestive of PAVMs are stigmata of right-to-left shunting (dyspnea, hypoxemia, cyanosis, cerebral embolism, brain abscess), unexplained hemoptysis, or hemothorax. We present a case of a young man who presented to the Emergency Department complaining of dyspnea, polycythemia, and persistent hypoxemia. Angio-computed tomographic scan of the chest detected multiple PAVMs. PAVMs are uncommon in the general population, but they represent an important consideration in the differential diagnosis of common pulmonary problems, including hypoxemia, pulmonary nodules, and hemoptysis.
\end{abstract}

\section{Introduction}

Pulmonary arteriovenous malformations (PAVMs) allow a proportion of the right ventricular volume to bypass gas exchange, filtration, and other functions of the pulmonary capillary bed. The size of the right-to-left shunt determines the degree of hypoxemia and respiratory failure. PAVMs of any size allow paradoxical emboli that may cause ischemic strokes, myocardial infarction, cerebral (brain) and peripheral abscesses. Less frequently, PAVMs may cause hemoptysis, hemothorax, and/or maternal death in pregnancy. Due to compensatory adaptations, respiratory symptoms are frequently absent or not recognized.

The differential diagnosis of PAVMs is wide and depends on the presenting complaint. Although

Correspondence: Lucio Brugioni, Department of Internal Medicine and Critical Area, Policlinico of Modena, Italy. E-mail: brugioni.lucio@aou.mo.it

Key words: Pulmonary arteriovenous malformation; right-toleft shunt; dyspnea; hypoxemia; embolotherapy.

Received for publication: 26 June 2019.

Accepted for publication: 19 August 2019.

This work is licensed under a Creative Commons Attribution NonCommercial 4.0 License (CC BY-NC 4.0).

${ }^{\circ}$ Copyright: the Author(s), 2019

Licensee PAGEPress, Italy

Italian Journal of Medicine 2019; 13:244-246

doi:10.4081/itjm.2019.1195
PAVMs are unusual causes of pulmonary nodules, dyspnea, hemoptysis, stroke, and cerebral abscess, they should be suspected when more common etiologies for these symptoms and signs are absent.

\section{Case Report}

A 19-year-old man presented to the Emergency Department after occasional finding of polycythemia (hemoglobin $19.8 \mathrm{gr} / \mathrm{dL}$, hematocrit 59\%) and persistent hypoxemia $\left(\mathrm{SaO}_{2}<85 \%\right)$ even though he underwent supplemental oxygen therapy. In his medical history, only autoimmune thyroiditis is reported. The clinical exam revealed clubbing fingers; also, his grandfather presented this sign. The arterial blood gas test showed hypoxemic respiratory failure with respiratory alkalosis $\left(\mathrm{pH} 7.45, \mathrm{pO}_{2} 46 \mathrm{mmHg}\right.$, $\mathrm{pCO}_{2} 29 \mathrm{mmHg}, \mathrm{SpO}_{2} 83 \%, \mathrm{HCO}_{3} 22.5 \mathrm{mmol} / \mathrm{L}$ ). Metabolic panel, thoracic X-rays, electrocardiogram and echocardiography were all normal. Angio-computed tomographic (CT) scan of the chest detected multiple PAVMs in subsegmental arteries and veins of the left lung with marked dilatation of the left pulmonary vein. Saline bubble contrast echocardiography (TTCE) showed severe PAVM with right-to-left shunt. The patient was treated with injection of embolic material by selective angiographic catheterization of the biggest PAVMs (embolotherapy). The procedure was repeated after few months to complete the closure of remaining PAVMs. The patient subsequently was in good general conditions, asymptomatic for dyspnea, with persistent mild desaturation on exertion. Other tests were made for detecting other PAVMs associated with hereditary hemorrhagic telangiectasia (HHT), in particular in 
splanchnic and cerebral districts, which were normal.

\section{Discussion}

Pulmonary arteriovenous malformations are abnormal communications between pulmonary arteries and veins. Approximately $80-95 \%$ of PAVMs are associated with HHT, ${ }^{1,2}$ also known as Osler-WeberRendu syndrome. PAVMs may be present from birth and have usually completed major development by adult life, although they can enlarge later in life, for example, during pregnancy or other alterations in pulmonary hemodynamics. ${ }^{3}$ The clinical features suggestive of PAVMs are stigmata of right-to-left shunting (dyspnea, hypoxemia, cyanosis, cerebral embolism, brain abscess), unexplained hemoptysis or hemothorax. ${ }^{4}$

These include life-threatening hemorrhage, symptoms and complications from paradoxical embolization, such as stroke and brain abscess. The primary determinants of stroke and abscess risks were unrelated to severity of PAVMs. There was a marginal association between brain abscess and low oxygen saturation. For ischemic stroke, there was no association with any marker of PAVM severity, or with conventional neurovascular risk factors. Surprisingly, low mean pulmonary artery pressure was strongly associated with ischemic stroke. ${ }^{5}$ Although the literature prior to $2000^{6}$ suggested that most PAVMs were associated with pulmonary symptoms, studies since 2000 describe pulmonary symptoms in only 20 to 65 percent (approximately 40 percent) of patients, and the remainder are asymptomatic, and they are typically found incidentally upon chest imaging. ${ }^{7}$ For most patients with suspected PAVMs, the initial test of choice to evaluate the presence of a right-to-left shunt is TTCE (also known as bubble echocardiography). This test has high sensitivity and so it is the reason why TTCE was recommended by the international HHT guidelines committee as the initial PAVM screening test. ${ }^{8}$ Although PAVMs may be clearly visible on chest radiographs, many are not, and the chest radiograph has been reported as being normal in 10 to $40 \%$ of instances where clinically significant PAVMs were present. ${ }^{9} \mathrm{CT}$ is generally considered the gold standard investigation for diagnosing PAVMs and demonstrating their size and extent before therapy. This imaging modality defines PAVM number, size, nature, and suitability for embolization. ${ }^{10}$ The feeding artery diameter, PAVM-related symptoms, and the patient's ability to tolerate the procedure are the most important factors for selecting patients who are candidates for treatment. When indicated, most patients are treated with embolotherapy that is recommended for first-line treat- ment. ${ }^{11}$ PAVM treatment reduces risks from paradoxical emboli and improves oxygenation, other physiological parameters, symptoms exacerbated by right-to-left shunting and hemorrhage. ${ }^{12}$ PAVM embolization significantly reduced ischemic stroke rate. ${ }^{4}$ Surgery treatment is another option in case of embolization failure.

\section{Conclusions}

PAVMs are uncommon in the general population, but they need to be considered in differential diagnosis of common pulmonary signs and symptoms such as hypoxemia, pulmonary nodules and hemoptysis. PAVMs are often associated with malformations in other body districts, which need to be evaluated in case of suspected HHT syndrome. PAVMs morbidity and mortality are related to the development of serious complications including stroke, brain abscess, chronic hypoxemic respiratory failure and life-threatening hemoptysis or hemothorax.

\section{References}

1. Govani FS, Shovlin CL. Hereditary haemorrhagic telangiectasia: a clinical and scientific review. Eur J Hum Genet 2009;17:860-71.

2. McDonald J, Bayrak-Toydemir P, Pyeritz RE. Hereditary hemorrhagic telangiectasia: an overview of diagnosis, management, and pathogenesis. Genet Med 2011; 13:607-16.

3. Shovlin CL, Jackson JE. Pulmonary arteriovenous malformations and other pulmonary-vascular abnormalities. In: Mason B, Murray N, eds. Murray and Nadel's textbook of respiratory medicine. 6th edn. Pennsylvania: Elsevier Saunders; 2015.

4. Shovlin CL. Pulmonary arteriovenous malformations. Am J Respir Crit Care Med 2014;190:1217-28.

5. Shovlin CL, Jackson JE, Bamford KB, et al. Primary determinants of ischaemic stroke/brain abscess risks are independent of severity of pulmonary arteriovenous malformations in hereditary haemorrhagic telangiectasia. Thorax 2008;63:259.

6. Gossage JR, Kanj G. Pulmonary arteriovenous malformations. A state of the art review. Am J Respir Crit Care Med 1998;158:643.

7. Angriman F, Ferreyro BL, Wainstein EJ, Serra MM. Pulmonary arteriovenous malformations and embolic complications in patients with hereditary hemorrhagic telangiectasia. Arch Bronconeumol 2014;50:301.

8. Faughnan ME, Palda VA, Garcia-Tsao G, et al. HHT Foundation International - Guidelines Working Group. International guidelines for the diagnosis and management of hereditary haemorrhagic telangiectasia. J Med Genet 2011;48:73-87.

9. Shovlin CL, Wilmshurst P, Jackson JE. Pulmonary arteriovenous malformations and other pulmonary aspects of HHT. Eur Respir Monogr 2011;54:218-45. 
10. Woodward CS, Pyeritz RE, Chittams JL, Trerotola SO. Treated pulmonary arteriovenous malformations: patterns of persistence and associated retreatment success. Radiology 2013;269:919-26.

11. Hsu CC, Kwan GN, Thompson SA, et al. Embolisation for pulmonary arteriovenous malformation. Cochrane Database Syst Rev 12;8:CD008017.

12. Shovlin CL, Donaldson C, Wort K; British Thoracic Society. British Thoracic Society clinical statement on pulmonary arteriovenous malformations. Thorax 2017;72 :1154-63. 